sciendo Порівняльна професійна педагогіка 8(3)/2018

DOI: $10.2478 /$ rpp-2018-0045

Undergraduate Student, FARAZ YUSUF KHAN Electronics \& Communication Engineering Department,

Faculty of Engineering, Integral University, India Address: Kursi Road, Lucknow, Uttar Pradesh, India

E-mail: ferez1905@outllook.com

Undergraduate Student, AADITYA RANJAN SRIVASTAVA

Mechanical Engineering Department, Integral University

Address: Integral University, Kursi Road, Lucknow Uttar Pradesh, India, 226024

E-mail: adityar@iul.ac.in

Doctoral Student, SHRISH BAJPAI

Electronics \& Communication Engineering Department,

Dr. A.P.J. Abdul Kalam Technical University, Address: Sector 11, Jankipuram Vistar, Lucknow, Uttar Pradesh, India E-mail: shrishbajpai@gmail.com

Professor, NAIMUR RAHMAN KIDWAI, Jahangirabad Educational Trust Group of Institutes, Address: Jahangirabad Fort, Jahangirabad, Barabanki, Uttar Pradesh, India E-mail: naimkidwai@gmail.com

\title{
MICROWAVE ENGINEERING AS PART OF UNDERGRADUATE CURRICULUM FOR ELECTRONICS ENGINEERING AND AS SPECIALIZATION DISCIPLINE FOR POSTGRADUATE STUDIES IN INDIA
}

\begin{abstract}
The establishment and development of Radio frequency $(R F)$ and Microwave Engineering (ME) from its inception in Electrical and Electronics Engineering to having its own distinct identity in the $21^{\text {st }}$ century has been explored in this paper. Overview of contributions by India to the field of RF and Microwave Engineering have been mentioned. Present paper deals with the field of RF and Microwave Engineering, especially the standard of its education in India. This paper explores the multidisciplinary nature of a RF and Microwave engineer and analyses how an RF and a Microwave engineer can contribute to the industry. Hierarchy and structure of Indian education system concerned with Engineering and Technology have been reviewed along with options and incentive available to aspiring researchers in the field of RF and Microwave Engineering. Nuances of dual degree program have been discussed. Job opportunities in government sector and private sector have been analyzed. A $R F$ and Microwave engineer can find employment opportunities in premier government bodies such as Indian Space Research Organisation (ISRO) and Defence Research and Development Organisation (DRDO) along with private corporations in the rapidly growing telecom sector of India. Handheld device-based apps and web-based database programs
\end{abstract}


initiated by the Government of India have been discussed. It has been concluded that RF and Microwave engineers will play a decisive role in the development of India. Performance of $a R F$ and Microwave engineer will be a major factor in deciding the magnitude of performance of the Indian Defence Forces. The authors of this paper have suggested some steps to the Government of India which can help RF and Microwave Engineering education reach its maximum potential.

Keywords: RF and Microwave Engineering, Technical Education System, Engineering Education in India.

\section{INTRODUCTION}

RF and Microwave Engineering involve constituting electromagnetic waves $(1 \mathrm{GHz}-300 \mathrm{GHz})$ for the development of microwave systems, components and circuits. Microwave Engineering's application has helped Human Civilization in numerous ways. It has enabled mankind to achieve efficient modes of communication by improving directivity and reducing antenna size, transmitting messages around the world and perhaps the most seen product of Microwave Engineering is the Microwave Oven which can be found in every third house of any developed city (Pasachoff, 2015).

The foundations of RF and Microwave Engineering are rooted in Electromagnetic Theory. In 1873 a retired Scottish college professor named James Clerk Maxwell unveiled to the world that combining electrical energy and magnetic it was possible for a wave to travel in space. A German scientist by the name of Heinrich Hertz confirmed James Clerk Maxwell's theory which is used by academia-industry till this day. The next major contribution came from an English Electrical Engineer, Oliver Heaviside who adapted Maxwell's equation into a vector-calculus form which then found application in the Transatlantic Cable and Telegraph Systems (Maver, 1918).

India contributed to the development of Microwave Engineering through Sir Jagdish Chandra Bose who demonstrated ringing a bell and blowing up gunpowder from a remote location using wavelengths ranging from $2.5 \mathrm{~cm}$ to $5 \mathrm{~mm}$. Sir Jagdish Chandra Bose's work has stood the test of time as an exceptional feat since his work was based on a frequency of $60 \mathrm{~Hz}$ in the late $19^{\text {th }}$ century (Mukherjee, \& Sen, 2007). Russell and Sigurd Varian, popularly known as the Varian brothers, are credited with inventing the Klystron tube. Modification of Varian brother's Klystron tube is utilized to administer millimeter wave power to this day (Caryotakis, 1998). Microwave Engineering got its due attention during World War II when it was applied in weapons development and radar technology. Radio Proximity Fuse was used by participating parties as an efficient way to detonate a shell near its target. Chain Home Radar Air-Defense System can be credited to saving numerous British lives by detecting enemy aircrafts during the Battle of Britain. This incident brought the world's attention to the potential of Microwave Engineering. HAH Boot and JT Randall, two British scientists, are credited for inventing the "Cavity Magnetron" utilizing oscillating principles to generate electromagnetic waves at the magnitude of 1000 times, which is the power of any available microwave generator at that time (Boot, \& Randall, 1976). Microwave Engineering technology, developed during World War II, proved to be a boon for civilian applications as Percy Lebaron Spencer invented a household device used for heating food through microwaves, aptly called the Microwave Oven. Key developments in the sphere of RF and Microwave Engineering took place during the turn of the $20^{\text {th }}$ century. Leo Esaki who won the Nobel Prize for Physics in 1973 is a house old name for Microwave Engineers for inventing the Esaki Tunnel Diode while 
sciendo Порівняльна професійна педагогіка 8(3)/2018

Comparative Professional Pedagogy 8(3)/2018

being employed at Sony Corporation, Japan. JB Gunn's invention of the "Gunn" Diode proved instrumental in the manufacture of pocket friendly microwave oscillators. A Microwave Engineer of the $21^{\text {st }}$ century possesses the conceptual knowledge of an electrical engineer, electronic engineer and telecommunication engineer. A microwave engineer is responsible for application of these concepts in the production and design of Microwave Systems (Sinha, 2018).

India stands second on the list of world's most populated country, seventh on the list of world's largest country and first on the list of largest population in the world. But from a socioeconomic development perspective the key fact is that India has one of the largest populations of engineering students in the world. After achieving independence in 1947 India's leaders supervised the rapid industrialization of the country (Khare et al., 2016). During the late part of the $20^{\text {th }}$ century India witnessed the first telecom revolution and during the early part of the $21^{\text {st }}$ century India is witnessing electronics revolution and second telecom revolution. Indian government's premier initiative "Make in India" program aims to generate employment for local population by calling multinational companies to setup manufacturing stations with research and development units in India. For the success of "Make in India" program it is imperative for microwave engineers of India to contribute their best abilities towards telecommunication sector, electronic sector and defense sector. Robust framework of engineering and technology education in India has allowed a smooth transition from gaining knowledge to their implementation in industrial applications (Bajpai et al., 2016).

\section{THE AIM OF THE STUDY}

Our study is aimed at: finding the prevalent status specific to RF and Microwave engineering education in India; collecting data related to RF and Microwave Engineering from various premier institutions of India such as Indian Institute of Engineering Science and Technology and Indian Institute of Space Science and Technology; overviewing hierarchical framework of RF and Microwave Engineering Education in India and scope of job opportunities in public sector as well as a private one.

\section{THEORETICAL FRAMEWORK AND RESEARCH METHODS}

The problem of engineering education has been studied by prominent researchers all over the world (S. Bajpai, P. Bharati, A. Chatterjee, S. Khare, W. Maver, S. Sinha, A. Srivastava et al.). The principles of this research are to collect data related to the RF and Microwave engineering education associated with its status in India from the technical institutes in India. Similar type of work has been performed by the researchers in the field of control, ceramic, manufacturing, material science and renewable energy engineering (Srivastava et. al, 2018). Data for subjects in courses related to RF and Microwave Engineering have been taken from websites of regulating bodies concerned with Engineering and Technology, such as All India Council for Technical Education (AICTE) and University Grants Commission (UGC). Syllabus for UG and PG courses concerned with RF and Microwave Engineering has been analyzed from websites of Institutes of National Importance in India, while syllabus for Doctoral studies in RF and Microwave Engineering has been scrutinized from Indian Institute of Technology Kanpur's webpage. The obtained information has been processed with the help of such methods as deduction and induction, synthesis and analysis.

\section{RESULTS}

As of the year 2017-18, India has managed to establish 4587 Institutions which offer a Diploma in Engineering degree to interested students (Handbook, 2012). Microwave engineering is offered as a compulsory theory subject in some three-year diploma courses (Khare et al., 2015). At the time of writing there are no institutions which offer a Diploma in Engineering degree with respect to RF and Microwave engineering. To be eligible for diploma degree a student must pass their $10^{\text {th }}$ board exam from a recognized educational 
board with math and science as compulsory subjects. Students are required to perform exceptionally well in their $10+2$ examinations from a recognized educational board with math and science as compulsory subjects to be eligible for Joint Entrance Examination held by The Central Board of Secondary Education (CBSE) in two stages - a main one and an advanced one. Performance of a student in Joint Entrance Examination (JEE) is used as the sole parameter for admissions to India's Institutes of National Importance concerned with engineering and technology, namely Indian Institutes of Technology (IIT), National Institutes of Technology (NIT) and Indian Institute of Information Technology (IIIT) along with several other institutions (Bajpai et al., 2016).

Indian Institute of Technology provides engineering education with the concepts of Engineering and their application in industry at par with the best universities of the world. A graduate of Indian Institute of Technology is expected to solve real world problems of social and economic nature. Admissions for a postgraduate program in Engineering and Technology are carried out in 2 stages: 1) a candidate has to pass Graduate Aptitude Test in Engineering held by an IIT every year upon clearing the cut off for his desired institution; 2) a candidate faces an interview for admission in the program that he has applied for (Bajpai, \& Akhtar, 2017). Selected candidates for post-graduation in Engineering and Technology are provided with monthly financial assistance of Rs. 12400 for 8 hours of work per week.

Postgraduate admission for Engineering and Technology is held by the institute's concerned department. Only candidates with a Cumulative Grade Point Average (CGPA) of 6.00 on a 10-point scale or $60 \%$ aggregate during their Master's degree are eligible. Candidates must pass National level cut-off of GATE, University Grants CommissionNational Eligibility Test (UGC-NET), Council of Scientific \& Industrial Research-National Eligibility Test (CSIR-NET) and Junior Research Fellowship examinations for admissions to doctoral programs at the institute of their choice (Bajpai \& Kidwai, 2017). Financial Assistance in the form of Institute Assistantship (IA) of Rs.25000 is provided for the first two years which is incremented by Rs. 3000 for the next two years resulting in IA of Rs.28000. Indian academia works in collaboration with Indian industry in a good way to increase economic growth. This relation extends to providing financial assistance to Post Graduate students and Doctoral Students for their academic endeavours. Public sector bodies such as Council of Scientific \& Industrial Research (CSIR), Department of Atomic Energy (DAE), Ministry of Human Resource Development (MHRD), Defense Research and Development Organisation (DRDO), Directorate of Education (DOE) and Naval Research and Army Technology Board are some of the many enterprises that take pride in providing financial assistance to Master's and Doctoral Students in order to accelerate as well as promote the research and development of their academic efforts. Students can opt for diploma in Microwave Engineering from a few polytechnics across India since the structure of Microwave Engineering is composed of common subjects related to Electrical Engineering and Electronics Engineering (Bajpai, \& Kidwai, 2018). Set up in 1945, India Council for Technical Education regulates diploma level courses on Microwave Engineering. At bachelor level Microwave Engineering is an integral part of Electrical Engineering curriculum and Electronics Engineering curriculum. Students are introduced to basics of Microwave Engineering through the subject known as Electromagnetic Theory or Electromagnetic Engineering. In second year RF and Microwave Engineering is a compulsory subject for electronics engineers and electrical engineers. Lab work is done in the field of RF and Microwave Engineering involving Esaki tunnel diode, Schottky diode, E-Plane waveguide, H-Plane waveguide, E-H Plane waveguide and other types of microwave systems. For 


\section{S sciendo Порівняльна професійна педагогіка 8(3)/2018}

Comparative Professional Pedagogy 8(3)/2018

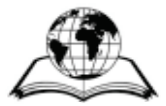

completion of graduate degree in Microwave Engineering students must assemble a project in their final year. Project work generally involves wireless communication, robotics, remote sensing and home automation. A quintessential course structure for postgraduate program in RF and Microwave Engineering has been provided by Department of Electronics and Communication Engineering, Indian Institute of Technology-Roorkee. During the first year Post Graduate program theory subjects include Microwaving Engineering, Advanced EMFT, Designing of Transmitting and Receiving Antennas. Subjects which constitute laboratory course work involve students' performing experiments in Microwave Lab and Wireless Communication Lab. Elective subjects from the field of Electronics Engineering, Communication Engineering and Applied Sciences, such as Fibre Optic System, Radar Signal Processing, Microwave Imaging, Digital Communication Systems, RF CMOS Transceiver Design and Advanced Applied Mathematics are included. Second year post graduation for $\mathrm{RF}$ and Microwave Engineering is entirely dedicated to dissertation of a chosen topic. Dissertation of the concerned student is verified by an examiner from another institution in India. Undergraduate degree program and post graduate degree program are amalgamated to form a 5-year dual degree course in RF and Microwave Engineering, which is provided by some premier Institutes of National Importance concerned with Engineering and Technology.

\section{Status of RF and ME in NITs}

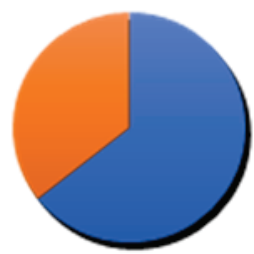

- NITs having courses related to RF and ME NITs nothaving courses related to RF and ME

Fig. 1

St at us of RF and ME in IITs

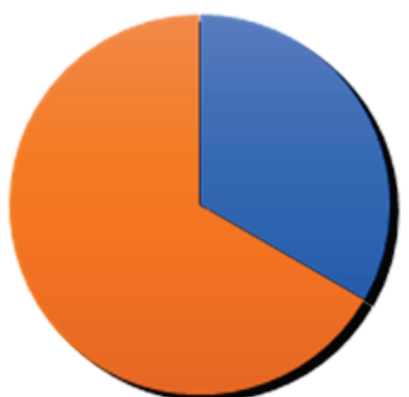

- RF and ME PG course availiable $1 \mathrm{RF}$ and ME PG course not availiable "

Fig. 2. 
Availability of UG and PG programs for RF and Microwave Engineering in India's premier institutes classified as Institutes of National Importance has been illustrated in Figure 1 and Figure 2 respectively.

At doctoral level a student is required to perform theoretical and real time analysis of their chosen topic for doctoral analysis. Indian Institute of Technology (Kanpur) has developed emulation worthy model for research in RF and Microwave Engineering. Areas of specialisation in RF and Microwave include microwave material processing, nanophotonics, nanoplasmonics, printed antennas, computational electromagnetics, wireless power transfer and dielectric resonators.

Considering that RF and Microwave Engineering origins lie within Electrical and Electronics Engineering it is not at all surprising that some part of RF and Microwave Engineering curriculum is the same as Electrical Engineering curriculum, Electronics engineering curriculum and Telecommunication Engineering curriculum. Interdisciplinary relation has allowed RF and Microwave Engineering students to refer to standard textbooks related to Electrical Engineering, Electronics and Telecommunication Engineering from renowned international authors, including Adel S Sedra, DM Pozar, Michael Steer, De Los Santos and RL Boylestad. Engineering students across India often referred to books from international authors for deep understanding of concepts. Technical universities of India, such as Gujarat Technical University (GTU), Rajasthan Technical University (RJTU) and Dr. A.P.J. Abdul Kalam Technical University (APJAKTU) use text books authored by Wali Sandeep, Khedkar Ashok, Joshi Jayshi, Urvashi Shah and M Kulkarni for RF and Microwave Engineering curriculum. National Program on Technology Enhanced Learning (NPTEL) was launched at the end of the $20^{\text {th }}$ century and the beginning of the $21^{\text {st }}$ century. Seven oldest IITs of India in conjunction with Indian Institute of Science (Bangalore) decided to take advantage of India's first Telecom revolution and launch a web-based database of Engineering and Applied Sciences curriculum as prescribed by All India Council for Technical Education. Arrival of NPTEL was and continues to be a blessing for aspiring engineers and engineering students across India. Being a web-based database, NPTEL has saved a colossal amount of spending on infrastructure (Ananth, 2011). The Second Telecom revolution of India during which mobile networks were improved in proportion to mobile data charges being decreased has acted as a force multiplier for NPTEL. RF and Microwave Engineering students have access to video lectures provided by IIT Kharagpur and IIT Bombay on NPTEL. Duration of courses dedicated to RF and Microwave Engineering is generally 8 weeks. Students are subjected to weekly tests, assignments and pan-India online examination. Upon achieving required passing marks a candidate receives a certificate validating the successful completion of his/her course. Some institutions in India offer extra credits to students for successful completion of a NPTEL course.

Ministry of Human Resource Development (MHRD), Government of India in collaboration with All India Council for Technical Education (AICTE) have recently launched Swayam - an online platform similar to NPTEL which caters to school level courses, graduation level courses and post-graduation level courses. Swayam has no age restrictions and can be accessed by anyone with Internet connection. Government of India has also provided the SWAYAM platform with handheld device applications which can be downloaded at no cost from Android Play Store, Apple's I-store and Microsoft's Windows Store (Sahoo et. al, 2018).

Employment opportunities. Public Sector Undertaking which is controlled by the Government of India recruits RF and Microwave engineers through National Level 


\section{S sciendo Порівняльна професійна педагогіка 8(3)/2018}

Graduate Aptitude Test in Engineering followed by a selection procedure including personal interview. Graduate Aptitude Test in Engineering marks form the majority of selection criteria in the entire recruitment process for public sector undertakings. Bharat Sanchar Nigam Limited and Maharashtra Telecom Nigam Limited are major Public Sector Undertakings concerned with telecom sector in India. Both of these corporations recruit RF and Microwave engineers. India's premier institution for development of weapons systems, the Defence Research and Development Organisation (DRDO), recruits RF and Microwave engineers and employs them for various laboratories, mainly Microwave Tube Research \& Development Centre (MTRDC), Electronics \& Radar Development Establishment (LRDE), Laser Science \& Technology Centre (LASTEC), Defence Electronics Research Laboratory (DLRL) and Defence Avionics Research Establishment (DARE). Candidates can also find employment opportunities in Indian Defence Forces Military Engineering Service. Since the Rapid acceleration of Information Technology sector in India the trend has been that RF and Microwave Engineering graduates have abandoned their core branch and opted for widely available jobs in software and consulting corporations (Fig. 3).

\section{Employment opportunities for RF and ME Engineers in Indian} Defence Agencies

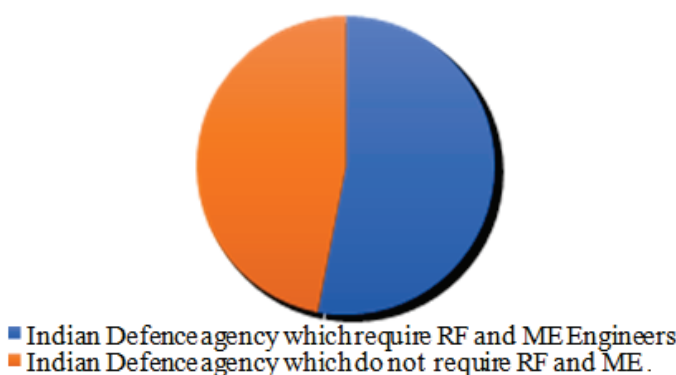

Fig. 3

RF and ME employment opportunities provided by Indian Space Agencies

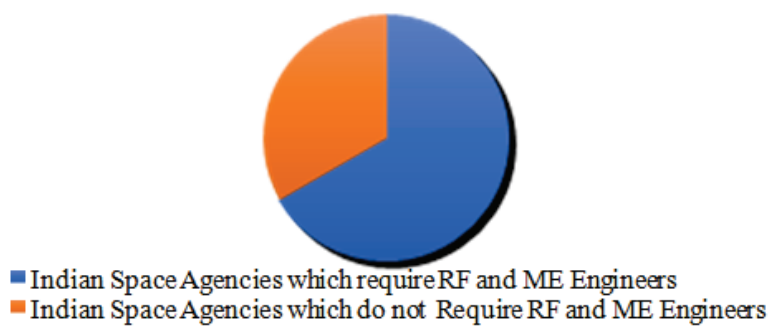

Fig. 4 
Indian Space Research Organization (ISRO), widely known as the institute that made headlines for successful launch of its pocket friendly Mars Orbiter Mission (MOM) at the first attempt, recruits RF and Microwave engineers where they render their services in various satellite organizations of ISRO, namely ISRO Satellite Centre (ISAC), Space Applications Centre (SAC), National Remote Sensing Centre (NRSC), Laboratory for Electro-Optics Systems (LEOS) and Indian Institute of Remote Sensing (IIRS) (Fig. 4).

Among private corporations, telecommunication sector in India has the majority of $\mathrm{RF}$ and Microwave engineers employed. RF and Microwave engineers in India were also employed by Reliance Jio, a mobile network operator that dramatically changed the face of Telecommunication industry in India by offering 4G VOLTE connectivity at inexpensive rates and competitive prices (Kumar et. al, 2018). RF and Microwave engineers are highly desired and heavily recruited by the telecom sector as India forms the second largest subscriber base with the third highest number of internet users, most of whom access internet on their handheld devices.

It is through the dedication and hard work of RF and microwave engineers that we are at the doorstep of $5 \mathrm{G}$ communication. Although $5 \mathrm{G}$ communication networks are still under development, their spectrum has been formulated between 6 gigahertzes and 100 gigahertzes. Tis range of frequency lies well within the range of applications that microwave engineers have already been working under (Pandey et al., 2015). India has the largest youth population in the world with the rapid advancement of telecommunication networks in the country aspiring engineering graduates to look at RF and Microwave Engineering as a lucrative option to achieve employment.

Indian Space Research Organization (ISRO), widely known as the institute that made headlines for successful launch of its pocket friendly Mars Orbiter Mission (MOM) at the first attempt, recruits RF and Microwave engineers where they render their services in various satellite organizations of ISRO, namely ISRO Satellite Centre (ISAC), Space Applications Centre (SAC), National Remote Sensing Centre (NRSC), Laboratory for Electro-Optics Systems (LEOS) and Indian Institute of Remote Sensing (IIRS) (Fig. 4).

Among private corporations, telecommunication sector in India has the majority of $\mathrm{RF}$ and Microwave engineers employed. RF and Microwave engineers in India were also employed by Reliance Jio, a mobile network operator that dramatically changed the face of Telecommunication industry in India by offering 4G VOLTE connectivity at inexpensive rates and competitive prices (Kumar et. al, 2018). RF and Microwave engineers are highly desired and heavily recruited by the telecom sector as India forms the second largest subscriber base with the third highest number of internet users, most of whom access internet on their handheld devices.

It is through the dedication and hard work of RF and microwave engineers that we are at the doorstep of $5 \mathrm{G}$ communication. Although $5 \mathrm{G}$ communication networks are still under development, their spectrum has been formulated between 6 gigahertzes and 100 gigahertzes. Tis range of frequency lies well within the range of applications that microwave engineers have already been working under (Pandey et al., 2015). India has the largest youth population in the world with the rapid advancement of telecommunication networks in the country aspiring engineering graduates to look at RF and Microwave Engineering as a lucrative option to achieve employment.

\section{CONCLUSIONS}

$\mathrm{RF}$ and Microwave Engineering plays a crucial role in advancement of weapon systems, military communication systems and civil and communication systems. It is an 
sciendo Порівняльна професійна педагогіка 8(3)/2018

Comparative Professional Pedagogy 8(3)/2018

emerging field in terms of Engineering and Technology. There are few colleges which provide bachelor's degree in RF and Microwave Engineering. The majority of dream institutions provide a post-graduation degree in RF and Microwave Engineering. Research areas for specialisation in RF and Microwave Engineering include lasers, computational electromagnetics, finite-difference time-domain (FD-TD), technique and metamaterials. Given how fast the defense industry is growing in India, RF and Microwave Engineering presents itself as a possibility of employment for aspiring engineers. The authors of this paper would like to suggest that Microwave Engineering should be offered as an elective subject to Computer Science Engineering and Automobile Engineering students so that inter-disciplinary nature of RF and Microwave Engineering can expand. Special attention should be given to RF and Microwave Engineering with respect to Consumer Electronics with respect to Electronics and Communication Students.

We live in time when Internet of Things has enabled us to spend our regular day to day activities in a very convenient manner. RF and Microwave Engineering Academia should include Internet of Things based subjects in RF and Microwave Engineering UG and PG curriculum with a focus on consumer electronics in order to make the transition from academy to industry easier for the upcoming RF and Microwave engineers. Elective subjects such as Artificial Intelligence and Programming in Computer Science and Engineering should be added in RF and Microwave Engineering UG and PG curriculum. Keeping the Indian Defense industry in mind RF and Microwave Engineering elective subjects should be offered to electrical, electronics and communication engineering branches. Recommendations for practical implementation of the suggested ideas are going to be presented in our further research publications.

\section{REFERENCES}

1. Ananth, M. (2011). National programme on technology enhanced learning (NPTEL): The vision and the mission. Technology for Education (T4E), 8.

2. Bajpai, S., Khare, S., \& Yadav, R. (2016). Control education in India: present \& future. IFAC-PapersOnLine, 49 (1), 813-818.

3. Bajpai, S., \& Khare, S. (2015). Mechatronics engineering education in India. Comparative professional pedagogy, 5 (4), 73-79.

4. Bajpai, S., \& Kidwai, N. R. (2017). Renewable Energy Education in India. Comparative Professional Pedagogy, 7 (4), 103-113.

5. Bajpai, S., \& Kidwai, N. R. (2018). Government's Effort In Controling Engineering Education in India. Comparative Professional Pedagogy, 8 (1), 75-83.

6. Bajpai, S., \& Akhtar, S. (2017). Industrial engineering education in India. Comparative professional pedagogy, 7 (3), 84-92.

7. Bajpai, S., Asif, S. S., \& Akhtar, S. A. (2016). Electromagnetic education in India. Comparative professional pedagogy, 6 (2), 60-66.

8. Boot, H. A., \& Randall, J. T. (1976). Historical notes on the cavity magnetron. IEEE Transactions on electron devices, 23 (7), 724-729.

9. Caryotakis, G. (1998). The klystron: A microwave source of surprising range and endurance. Physics of Plasmas, 5 (5), 1590-1598.

10. Handbook, Approval Process (2016). New Delhi: All India Council For Technoical Education. 
sciendo Порівняльна професійна педагогіка 8(3)/2018 Comparative Professional Pedagogy 8(3)/2018

11. Khare, S., Bajpai, S., \& Bharati, P. K. (2015). Production engineering education in India. Management and production engineering review, 6 (1), 21-25.

12. Khare, S., Chatterjee, A., Bajpai, S., \& Bharati, P. K. (2016). Manufacturing engineering education in India. Management and production engineering review, 7 (1), 40-44.

13. Kumar, A., Balaji, M., Krishna, U., \& Yadav, M. (2018). Jio-Bharti Airtel Data War and Strategy. In Harnessing Human Capital Analytics for Competitive Advantage (pp. 171-179). IGI Global.

14. Maver, W. (1918). Electricity, its history and progress. The Encyclopedia Americana.

15. Mukherjee, D. C., \& Sen, D. (2007). A tribute to Sir Jagadish Chandra Bose (1858-1937). Photosynthesis research, 91 (1), 1-10.

16. Pandey, M. K., Gaurav, A., \& Kumar, V. (2015). Social, technical and economic challenges of $5 G$ technology in Indian prospective: Still $4 G$ auction not over, but time to think about $5 G$ in India. Computer and Computational Sciences (ICCCS) International Conference on IEEE.

17. Pasachoff, N. (2015). The history of electromagnetic theory through the lives of its founders. Metascience, 24 (2).

18. Sahoo, J., Mohanty, B., Ratha, L., Meher, A., \& Sahu, J. K. (2018). Massive Open Online Courses and MOOCs-SWAYAM: An Assessment of Acceptance. In Library and Information Science in the Age of MOOCs (pp. 66-81). IGI Global.

19. Sinha, S. N. (2018). A brief history of Microwave Engineering. Retrieved from https://is.muni.cz/el/1431/podzim2015/F7061/um/L01History.pdf?lang=en.

20. Srivastava, A. R., Bajpai, S., \& Khare, S. (2018). Current Scenario of Ceramic Engineering Education in India. Comparative Professional Pedagogy, 8 (1), 84-88. 